\title{
THE IMPACT OF ELSTGEEST AND ALFKE'S QUESTIONING MODEL WITH MANIPULATIVES ON PHYSICS STUDENT TEACHERS' ABILITY TO GENERATE PRODUCTIVE QUESTIONS
}

\author{
Nyet Moi Siew, Sopiah Abdullah \\ University of Malaysia Sabah, Malaysia \\ E-mail:snyetmoi@yahoo.com, sopiah@ums.edu.my
}

\begin{abstract}
Question-asking is a basic skill required for the development of students' thinking. However, the way in which physics teachers conduct laboratory activities do not usually stimulate student thinking by asking productive questions. This study addressed this concern by investigating the physics student teachers' ability to generate productive questions using the Elgeest's and Alfke's questioning model with a set of manipulative learning (EAM) strategy. The manipulative consisted of simple electrical components that could be explored and manipulated. The study investigated if there was a difference in student teachers' productive questions in terms of number of questions in each category and level of thinking between before and after a lesson using EAM strategy. A further purpose was to find out students' thought regarding their experiences using the EAM strategy in generating productive questions. A total of 34 Third Year undergraduate physics student teachers took part in the study. They worked in a group of 3-4 to discuss and construct questions before and after the instruction. Student teachers'generated questions and written reflections were used as data collection methods. Questions were analyzed and classified according to Dillon's (1984) classification of questions: properties, comparisons, and causal relationships. It was found that before learning using the EAM strategy, student teachers tended to ask questions of the properties category. In contrast, students tended to pose causal relationship-type questions following instruction with the EAM strategy. Overall, the students indicated that the EAM strategy had increased their ability to generate productive questions at higher categories and cognitive levels. Physics teachers who conduct laboratory activities could use the EAM strategy to lead students in the generating productive questions that foster their thinking.
\end{abstract}

Key words: Elgeest's and Alfke's questioning model, manipulative, productive questions, physics student teachers, thinking.

\section{Introduction}

The developing thinking ability of individuals is one of the major purposes of education in most countries. This purpose can be achieved through a curriculum that emphasises thoughtful learning. Thoughtful learning is achieved when learners are actively involved in the teaching and learning process. Children as active learners have a natural disposition to wonder, to be curious, and to pose questions. Lipman (1988) believes that if children's natural curiosity and their desire to discover the world are integrated with philosophy, they can be more flexible and effective thoughtful individuals.

Findings in vast research have indicated that Philosophy for Children improve thinking skills, including critical thinking (Fisher, 1998). Philosophy for Children is an educational program aimed to develop and foster a thinking, learning and reasoning classroom by tapping 
Nyet Moi SIEW, Sopiah ABDULLAH. The Impact of Elstgeest and Alfke's Questioning Model with Manipulatives on Physics Student Teachers' Ability to Generate Productive Questions

PROBLEMS

OF EDUCATION

IN THE $21^{\text {st }}$ CENTURY Volume 54, 2013

100

children's natural curiosity and sense of wonder (Lipman, 1988). It was implemented for the first time in the States in 1970. The creator of the program, Matthew Lipman was teaching at Columbia University (N.Y.). He developed a curriculum where philosophical discussions about philosophical topics were the academic stuff that helped children to foster their thinking skills. Children were engaged in the search for meaning and enriching and extending their understanding. Philosopher G. Matthews (1984) shares how very young children are not only curious and can ask puzzling questions on philosophical issues but can also engage in philosophical discussion. The central pedagogical tool of Philosophy for Children is the community of inquiry. In the community of inquiry, students work together to generate and then answer their own questions about the philosophical issues contained in the stimulus materials.

To bring philosophical inquiry into natural science, teachers need to present their laboratory activities in a way that encourages scientific inquiry rather than following procedures to collect numbers and results. Rescher (1982) describes scientific inquiry as "a step-by-step exchange of query and response that produces sequences within which the answers to our questions ordinarily open up yet further questions". Questions such as "What might happen (or, what might have happened) if . . " have been used in philosophy to allow students to explain, predict and control events in a better and more productive way. Thus, if room for philosophical questions is encouraged as part of scientific inquiry process, students can make better sense of their educational experiences.

According to Elstgeest (1985), for scientific inquiry to be effective, science teachers should use productive questions to help learners advance in their thinking. Elstgeest defines productive questions as those stimulating questions which engage students in thinking, invite a closer look, a new experiment, or a fresh exercise (Elstgeest, 1985). Harlen (1985) further supported that productive questions stimulate productive physical or mental activity and reasoning in students, and take them forward in their thinking. Productive questions can further be classified into several sub-categories: attention focusing, measuring and comparing, comparison, action, and problem-posing (Elstgeest, 1985) and operational questions (Alfke, 1974).

Answering each category of productive question depends on evidence gathered from a learning experience; for example from a hands-on and minds-on science investigation. On the other hand, unproductive questions usually ask for some type of explanation (Harlen, 1996). One example of an unproductive question is the "why" question. If a teacher asks a student, "Why does a sinking object float?", and if the student does not know, the student will likely have no response. Instead, if the teacher asks, "Why do you think a sinking object floats?", the modified question become "productive" that gives every student the opportunity to tell the teacher what they think, even if they do not "know" the answer. According to Alfke (1974), the 'why' question can be refined into 'what if' questions that result in meaningful investigations or some method of obtaining first-hand observations that help students to answer the question. The 'what if' questions, or termed as operational questions are described as productive for the learner (Alfke, 1974). Operational questions can be directly investigated by manipulating variables in science experiments through eliminating, substituting, and increasing or decreasing the presence of a variable. The questions lead to a task which allows the student to work with materials and obtain first-hand evidence. Manipulation of variables is central to understanding cause-and-effect relationships in scientific inquiry, and operational questions are a means of encouraging students to think about such relationships. Students do not always ask operational questions or productive questions spontaneously, unless they are stimulated to think about such questions. Thus, generating productive questions in the community of inquiry is a field to be studied in this study. 


\section{Problem Statement}

Along with the changes in the theoretical foundations and nature of science, new approaches have been introduced into Malaysian Secondary School Revised Physics Curriculum. One of these most important approaches focuses on scientific and thinking skills (Ministry of Education, 2006, p.2). Scientific skills encompass science process skills and manipulative skills. Whereas, thinking skills can be categorised into critical thinking skills and creative thinking skills. Malaysian Curriculum for both pre-service and in-service teacher education has made clear the strategies science teachers should adopt that promote student's scientific and thinking skills. Asking higher order questions has been identified as an important teaching and learning strategy (Ministry of Education, 2006).

Despite question-asking playing an important role in helping students to become more intellectually engaged learners, a closer analysis of the several studies revealed that the questions asked in typical science classroom instructions are not directed to the stage of development of students' thinking ability (Ling, 2000, Subahan, 1999). Questions by teachers are posed mainly during lessons and not during experiments. The questions generated during experiments are to make students familiar with the scientific skills as opposed to going beyond the experiments to formulate high-level, thought-provoking ones (Subahan, 1999).

The trend of questions asked in classroom learning can be traced back from the teacher training curriculum in institutes and universities. The emphasis is given to Bloom's (1956) taxonomy that describes the questions categories according to mental tasks to be mastered, i.e., knowledge, comprehension, application, analysis, synthesis, and evaluation. However, Elstgeest (1985) stresses that questions should promote activity and reasoning, and invite the students to look closer and experiment. Chin (2002) also emphasizes that question posed in an investigation should be amenable to hands-on, manipulative activities where students can collect and process some original data to answer the question posed.

Accordingly, the development of the ability to generate productive questions that promote student scientific and thinking skills is crucial and needs to be fostered among student teachers. Teachers exert the greatest influence in the classroom through the way in which they engage students in thinking. Therefore, student teachers need to have a good understanding of productive questions and at the same time be competent in posing those questions. Accordingly, an effective instructional strategy which enhances productive questions asking needs to be identified for incorporation into the laboratory activities.

White (1977) has suggested that the ability to formulate questions is a skill which needs to be taught, and that the teacher could provide examples of how to form questions. One of the suggested examples is using question stems. King (1994) found that giving students thought-provoking question stems such as "What happen to ....if ...?." helped them to generate questions that prompted them to compare and contrast, infer cause and effect, note strengths and weaknesses, evaluate ideas, explain, and justify. Meanwhile, Jelly (1985) suggested that teachers could use anomalous stimulus materials as question stimulators, and that students can then generate questions as a result of observations and manipulation with those materials.

Question stems of Elstgeest (1985)'s and Alfke's (1974) questioning model are ideal for generating productive questions because they stimulate productive physical or mental activity and reasoning in learners. The manipulative, such as the set of science apparatus can act as stimulus materials which allow students to explore, manipulate, and trigger them to pose questions. This was particularly important to engage learners in the community of inquiry to both construct and evaluate the range of possible responses to a question while exploring those manipulatives. This would presumably induce student teachers to be more attentive to the tasks at hand and be more reflective in their own thinking and learning. Accordingly, this study attempted to examine whether learning using question stems of Elstgeest's (1985) and Alfke's (1974) questioning model with manipulatives (EAM) strategy could serve as a catalyst 
Nyet Moi SIEW, Sopiah ABDULLAH. The Impact of Elstgeest and Alfke's Questioning Model with Manipulatives on Physics Student Teachers' Ability to Generate Productive Questions

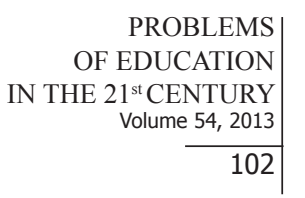

study was to investigate whether the use of the EAM strategy has possible influences on student teachers' ability to generate productive questions. Specifically, the present study set out to answer the following research questions:

1. Is there a difference in student teachers' productive questions in terms of number of questions in each category and level of thinking between before and after a lesson using EAM strategy?

2. What are the students' thought regarding their experiences using EAM strategy in generating productive questions?

The findings of the study would serve as a model for helping physics teacher to frame productive questions while planning and conducting their laboratory activities. Such a model would be useful in helping teacher to engage students in tasks that involve higher order thinking skills.

\section{Methodology of Research}

The study took place in University of Malaysia Sabah. A single group pretest-posttest research design was employed in the study, involving a total of 34 Third Year undergraduate pre-service physics student teachers. They were 20 (58.8\%) females and $14(41.2 \%)$ males. The age of the participants ranged from 22-23 years old. To determine whether the EAM strategy influenced student teachers' ability to generate productive questions, the student teachers' generated questions and written reflections were used as data collection methods.

\section{The Learning Process}

Prior to intervention, the student teachers were engaged in a task of generating questions. They worked in a group of 3-4 to discuss and construct questions that could be posed to students. Each group received one set of manipulative as stimuli to generate questions. The set of manipulative involved electrical components that consisted of 1.5 volt batteries, 2.5 volt bulbs, connecting wires, switch, ammeter (0-1A) and voltmeter (0-1V) which could be manipulated and explored. The manipulative prompted students to generate questions on the relationship between components of electric circuit and the voltage, resistance, current, and brightness of bulbs that were feasible for further investigations. For example, the student teachers could assemble pairs of circuit so that the bulb in one circuit was dimmer than the bulb in another circuit, and the possible question that could be generated was: Can you find a way to make one bulb in one circuit become dimmer than the bulb in the other circuit? The groups would then have to share their questions with the rest of the class using mahjong papers. The class was asked to give comments on questions generated by the groups. All the group generated questions were then collected for analysis. This way baseline information on student teachers' question level could be gathered and compared against those of after the intervention.

This was followed by an intervention to help physics student teachers attain the skills of generating productive questions. Students were provided a list of Elstgeest (1985)'s and Alfke's (1974) categories of questions. The student teachers were taught to begin questions using questions stems. Question stems refer to a set of Elstgeest (1985)'s and Alfke's (1974) category of question starters, which were designed to guide students through the question generating processes (Appendix A). Such thought-provoking question stems could help students generate questions that prompted them to compare and contrast, and infer cause and effect.

Following a 30-minute intervention, the class was asked to get back into their learning 
groups. Each group was advised to use the question stems as a reference guide to discuss and generate questions using the identical set of manipulatives as provided prior to the intervention.

\author{
PROBLEMS \\ OF EDUCATION \\ IN THE $21^{\text {st }}$ CENTURY \\ Volume 54, 2013
}

103

Each student in the group was given 10 minutes to list out their questions on a piece of paper. Secondly, the group leader would invite each group member to take turns to share her/his questions. Each group member could then comment on each other's questions. Thirdly, the group generated questions were then refined and written on pieces of mahjong paper.

Bearing in mind that providing feedback to questions constructed was important to challenge the students thinking, the researcher asked each group to critically evaluate the overall quality and the level of particular questions generated by the other groups. Besides that, the researcher used a grading system of "very good", "good", and "you can do better if..." as individual feedback to student teachers on the overall quality of their constructed questions. At the end of class session, all the group generated questions were collected for analysis. The student teachers were asked to write reflection upon the questions-generation class section to examine if the EAM strategy and scaffolding discourse improved the kind of questions they asked after the intervention. The whole learning session took about four hours.

\section{Classification of Questions According to Dillon's (1984) Taxonomy}

The student teachers' written questions were classified using three categories following Dillon's (1984) classification of questions. These categories were determined appropriate for questions classification in this study because the components found in Dillon's (1984) classification refer to the level of thinking required to provide the answers to those questions. These categories refer to: (1) Properties-answers to questions in this category describe the properties of the subject in question; (2) Comparisons-answering questions in this category requires a comparison between the subjects in question; and (3) Causal relationships-answering questions in this category requires finding the relation, correlation, conditionality, or causality of the subjects in question. In most cases, a further investigation is needed in order to answer questions in 'Causal relationships' category.

Accordingly, the Attention-focusing, and Measuring and Counting category of productive questions were classified into category "Properties" because such questions prompt learners to make qualitative and quantitative observation. On the other hand, the Comparison category of productive questions were classified into category "Comparisons" because such questions direct students to observe differences in shape, size, color, etc., between the subjects. Lastly, the Action, Problem-posing category of productive questions were classified into category "Causal relationships" because such questions require students to initiate a process of hypothesizing, predicting, thought-experimenting, and inferring cause and effect relationships. Operational questions (Alfke, 1974) that direct students to investigate science phenomena which manipulate variables through elimination, substitution, and increasing or decreasing the presence of a variable were also included in this category, since they indicate contradictory relationships.

The three categories-properties, comparisons, and causal relationship - were classified as first-, second-, and third-order categories, respectively, indicating their relative increase in thinking level. Usually, questions from the properties category referred to one variable, while questions from the comparisons and causal relationships categories referred to at least two variables. The causal questions were considered to be of the highest order of questions since "they represent the kind of knowledge that scientific inquiry is conceived ultimately to aspire to and that it is hoped eventually to attain" (Dillon, 1984). Accordingly, a model as follows was adopted to classify student teachers' generated productive questions in accordance with Dillon's (1984) Taxonomy. 
Nyet Moi SIEW, Sopiah ABDULLAH. The Impact of Elstgeest and Alfke's Questioning Model with Manipulatives on Physics Student Teachers' Ability to Generate Productive Questions

OF EDUCATI

IN THE $21^{\text {st }}$ CENTURY

Volume 54, 2013

Table 1. The productive question classification model.

\begin{tabular}{lll}
\hline Productive Questions & Dillon's (1984) category of question & Level of thinking \\
\hline $\begin{array}{l}\text { Attention-focusing } \\
\text { Measuring and Counting }\end{array}$ & Properties & First -order \\
Comparison Questions & & \\
$\begin{array}{l}\text { Action Questions } \\
\text { Problem Posing Questions }\end{array}$ & Comparisons & Second order \\
Operational Questions & Causal relationships & Third order \\
\hline
\end{tabular}

In the quantitative analysis of student teachers' questions, the change in the questions students asked is demonstrated by the number of questions in each category, rather than the change in the total number of questions. This is because the level of thinking required to provide the answers to those questions was considered the most important parameter, rather than the number of questions asked during a class session.

\section{Data Analysis}

The student teachers' written questions were pooled to a single file, before and after instruction respectively. Question categorization was carried out independently by the researcher and a physics teacher, both of whom have extensive background in physics education. The degree of agreement between the two independent categorizations was calculated by Kappa analysis (Agresti, 1990), using Crosstabs technique in the SPSS program. A summary of the crosstabs results for measure of agreement among the raters is presented in Table 2. The obtained Kappa is greater than 0.70 , which indicates that the inter-rater reliability is satisfactory.

\section{Results of Research}

\section{Analysis of Quantitative Data}

Most of the questions (69\%) posed by the trainees before the initiation of the learning using the EAM strategy were of the unproductive questions, in which they referred to the specific component of the circuit and answers can typically be found by referring to books (for example, "What is the use of battery?"), thus this category of question was eliminated from the analysis. Out of 40 productive questions posed by the students, $60 \%$ were of the properties category (Table 2). Answering a question in this category requires only declarative knowledge- knowing "what" and elicits the lowest level of thinking (Table 3), for example, "What are the electrical components needed in this circuit?". The students did not ask about significant details of specific components of an electrical circuit that they could actually explore or investigate.

Comparisons questions comprised only $10 \%$ of all the questions asked. Most of the questions in this category failed to properly operationalize the variables that could be investigated in an electrical circuit. For example, students use "Would the bulbs affect the resistance ..." instead of "Would the number of bulbs affect the resistance....."

Only $30 \%$ of the questions, at the initiation of the instruction, were classified into the third category. The questions classified in this category were all from action category of productive questions (Table 3). Most of the questions in this category did not have the structure of a question but, rather, were part of a phrase, for example, "What will happen if the circuit is connected the other way round?". The students also did not ask about specific variables and connection in the electrical circuit that could be referred to. 


\section{Table 2. Category of questions generated by student teachers before and after the initiation of the EAM strategy.}

\begin{tabular}{|c|c|c|c|}
\hline Category & $\begin{array}{l}\text { Prior to intervention }(\%) \\
=0.83\end{array}$ & $n=40, k$ & $\begin{array}{l}\text { After intervention (\%) } \\
\mathrm{n}=71, \mathrm{k}=0.91\end{array}$ \\
\hline Properties & 60 & & 26.8 \\
\hline Comparisons & 10 & & 14.1 \\
\hline Causal relationships & 30 & & 59.1 \\
\hline
\end{tabular}

Note: $\quad \mathrm{n}=$ number of questions accepted in this classification $\mathrm{k}=$ degree of inter-rater agreement among raters

Table 3. Examples of questions from each category prior to and after the intervention.

\begin{tabular}{|c|c|c|}
\hline $\begin{array}{l}\text { Category of } \\
\text { questions }\end{array}$ & Prior to Intervention & After Intervention \\
\hline Properties & $\begin{array}{l}\text { What are the electrical components needed } \\
\text { in this circuit? } \\
\text { What types of wire used in connecting the } \\
\text { circuit? } \\
\text { What is the scale used in the ammeter? } \\
\text { What is the reading of voltmeter and am- } \\
\text { meter in a series circuit? } \\
\text { What happen to the circuit when the switch } \\
\text { is closed or opened? }\end{array}$ & $\begin{array}{l}\text { What do you notice about the brightness of the bulb } \\
\text { when they are arranged in parallel? } \\
\text { What is the reading of the ammeter when a } 2.5 \text { volt } \\
\text { bulb is connected to the circuit? } \\
\text { What have you observed in the reading of ammeter } \\
\text { if one of the bulbs in the parallel circuit is not working } \\
\text { properly? } \\
\text { What do you notice about the reading of ammeter } \\
\text { when it is connected in parallel? }\end{array}$ \\
\hline Comparison & $\begin{array}{l}\text { Would the bulbs affect the value of current } \\
\text { and voltage in the circuit? } \\
\text { Would the bulbs affect the resistance of the } \\
\text { circuit? } \\
\text { Would the voltage of dry cells affect the } \\
\text { brightness of the bulb? } \\
\text { Is there any difference when the bulbs are } \\
\text { arranged in parallel and series? }\end{array}$ & $\begin{array}{l}\text { How much bigger in the reading of an ammeter when } \\
\text { connected to } 6 \text { volts battery compared to } 3 \text { volts } \\
\text { battery? } \\
\text { How are they different in the brightness of the bulbs } \\
\text { when they are connected in series and in parallel? } \\
\text { What do you notice about the brightness of the bulbs } \\
\text { when they are arranged in parallel compared with } \\
\text { those in series? } \\
\text { How are they different in the reading of ammeter if a } \\
\text { thicker wire is used? }\end{array}$ \\
\hline $\begin{array}{l}\text { Causal relation- } \\
\text { ship }\end{array}$ & $\begin{array}{l}\text { What will happen if the circuit is connected } \\
\text { the other way round? } \\
\text { What will happen to the circuit if one of the } \\
\text { batteries/bulbs is not functioning? } \\
\text { What happen if you connect the battery with } \\
\text { wrong polarity? } \\
\text { When more bulbs are added in the circuit, } \\
\text { is it possible the reading of the voltmeter } \\
\text { reduced, changed or increased? } \\
\text { If the more bulbs added to the circuit, is it } \\
\text { possible the brightness of the bulb reduced? }\end{array}$ & $\begin{array}{l}\text { What happen to the voltmeter ( } 0-1 \mathrm{~V}) \text { when } 1.5 \mathrm{~V} \\
\text { battery is being used? } \\
\text { What happen to the brightness of the bulb if another } \\
\text { identical battery is added to the parallel circuit? } \\
\text { What happen to the brightness of the bulb if more } \\
\text { number of bulbs are being added to the series } \\
\text { circuit? } \\
\text { How would you determine if there is a current flow in } \\
\text { the circuit? } \\
\text { What would happen to the reading of the voltmeter } \\
\text { when the length of the wires is increased? } \\
\text { Can you find a way to determine if the circuit connec- } \\
\text { tion will affect the ammeter's reading? } \\
\text { Can you find a way to make the series connection of } \\
\text { a battery casing into a parallel one? } \\
\text { How would the reading of an ammeter change if } \\
\text { one bulb is removed from the parallel circuit? } \\
\text { a longer wire instead of shorter wire is used? } \\
\text { increase/decrease the quantity of battery? }\end{array}$ \\
\hline
\end{tabular}


Nyet Moi SIEW, Sopiah ABDULLAH. The Impact of Elstgeest and Alfke's Questioning Model with Manipulatives on Physics Student Teachers' Ability to Generate Productive Questions

PROBLEMS

OF EDUCATION

IN THE $21^{\text {st }}$ CENTURY

Volume 54, 2013

106

There was a substantial increase in the total number of questions at higher category and level of thinking after instruction as indicated in Table 2. At this stage, $59.1 \%$ of the questions posed by the student teachers were of the third category - causal relationships-while $14.1 \%$ of the questions were of the second category, and $26.8 \%$ were of the first category (Table 2). An example of a Problem Posing question from the third category after learning via the EAM strategy is, "Can you find a way to determine if the circuit connection will affect the ammeter's reading? The student teachers clearly combine procedural knowledge (manipulation of the electrical component) with declarative knowledge (differentiation of current flow in the circuit). In doing so, the question invites students to integrate and apply their knowledge in new and creative ways to solve a given problem. Student teachers were also able to come up with prediction questions such as "What would happen to the reading of the voltmeter if the length of the wires is increased?", inviting students to think about the observational outcome of an event (what is seen) as a result of manipulations or changes in the independent variables.

A substantial increase in the total number of operational questions such as "How would the reading of an ammeter change if one bulb is removed from the parallel circuit? were also observed from this activity. The questions lead to a task which allows students to work with the electrical circuit and obtain first-hand evidence (additional examples appear in Table 3). 14.1\% of the questions were of the comparisons category, directing students to observe sharply the differences in voltage, current, resistance, and the brightness of the bulbs in different circuit connections, and recognize these differences as valuable information. $26.8 \%$ of the questions were of the properties category. Student teachers at this stage were able to generate questions that invited learners to give some significant detail in their observations or measurement on specific components in an electrical circuit (Tables 3).

\section{Analysis of Qualitative Data}

Student teachers' written reflections further provided evidence that the study sessions had affected their questions level. Student teacher explained how the sessions had helped him/ her in generating more and wider range of productive questions. Following are the student teachers' responses to experiences in the EAM strategy:-

\section{The EAM strategy: Acquiring skills in generating more categories of questions}

"When we were given the task to generate questions from the circuit that we connected, it was quite hard to construct the questions without proper guidelines. Luckily the given notes and lecture helps. During the commenting of the questions constructed by our classmates, I found that the comments enhance my understanding on how to construct better questions. I understand how to classify the questions. Meaning to say, prior to this class, I could only construct general questions but not different categories of questions." (S17)

"Before the intervention, the questions that we construct are more general, and there are many undefined words in the questions. After the intervention, the questions are clear, understandable and can be defined into different categories. Our classmates can easily understand what we want in the questions." (S10)

"Before intervention, the scope of our questions is limited. The questions focused more on answering the factual information of a complete circuit, and taking measurement. It took more time to think. After some guidelines were provided, more categories of questions could be constructed. The questions generated help us to gain more understanding about the topic." (S4)

"Before the intervention, the questions generated mainly focus on the existing electrical components in the experiment. But after the intervention, we were able to 
make more quality questions. We were also able to produce better questions which are more understandable and the main purpose of the questions is clear to the other group members. So, there is a change in the skill of generating questions using several categories." (S13)

"I think the questions generated after the intervention is more specific and systematic compared to the questions created before the intervention. Furthermore the questions created after the intervention are more objective than before. When our friends try to answer the questions, their answers are likely similar to what we want." (S27)

The student teacher, not having been exposed to the EAM strategy, at first found rather hard to construct questions. Her/his initial questions were general, unstructured and did not differ in terms of categories. Students also found that their questions were mostly from the properties category. However, with the provision of scaffolding via EAM strategy and constructive comments given by classmates, student teacher gradually warmed up to the task and was able to construct more categories of questions. The questions generated were clearer, more structured, specific, objective and understandable. In fact, the feedback session made students to think for themselves about the quality and categories of questions they had produced.

\section{The question stems: generating questions with higher categories and cognitive level}

Student teachers generally felt that question stems had helped them to successfully produce good questions, and their related remarks about question stems were: - "It helps me to generate various types of questions, from low level to a higher one,"; "It help us to generate clear questions and focus on the variables that we want students to explore,"; "The question stems provides us a guide on how to write questions in correct way. The structure of the questions is now clearer, more understandable, and the intended answers are more specific,"; "The provided descriptions in the question stem help us to categorize the questions easily. Now I can create questions ranging from low-level to a high-level of thinking,"; "The questions stems are helpful in classifying the types of generated questions clearly," and "It helps us to improve the previously generated questions, I can now make high-level questions".

Clearly, the question stems had provided student teachers a useful guide to construct questions of different categories and cognitive levels. Students appear more capable of generating higher-level of productive questions.

\section{The manipulative: Leading students to think of possible answers}

Science teachers did perceive the strength of manipulative and their related remarks were:

"The manipulative - electrical circuit helps me to think of a question that can be answered. This is because, when I suddenly think of a question, I try to experiment it with electrical circuit to find the answer. By manipulating the circuit, I can determine if the question can be answered by students in doing the experiment and whether it is safe to conduct the experiment."(S21)

"The manipulative can become a concrete material for us to look for possible answers for the proposed questions. Through the manipulation of the electrical components, we can determine if the generated questions are relevant and can be answered."(S18)

"The manipulative is helpful in preparing the steps of observing and asking ques- 
Nyet Moi SIEW, Sopiah ABDULLAH. The Impact of Elstgeest and Alfke's Questioning Model with Manipulatives on Physics Student Teachers' Ability to Generate Productive Questions

PROBLEMS

OF EDUCATION

IN THE $21^{\text {st }}$ CENTURY

Volume 54, 2013

tions. Overall, I found an easy way in generating questions. That is, by manipulating and observing the electrical circuit, we find ideas on the type of questions which can be generated and explored."'(S20)

"In general, the manipulative provides us a stimulus or condition to create the question that we want. Without the manipulative, the questions created may not be specific or are too general."(S31)

"The manipulative helps us finding out answers for the generated questions."

Obviously, most student teachers were successful in realizing the strength of manipulative in prompting them to think of possible responses to a question. Students appeared to have experienced the act of asking questions and the consequent search for answers using the manipulative.

\section{The manipulative: Stimulating ideas about investigable variables}

Students generally felt that the manipulative provides an outlet for stimulating ideas about variables as the following excerpts indicate:

"The manipulative helps us to see and observe the real situation of the circuit. By manipulating and observing the circuit, it helps us to think of kinds of variables which can be investigated in the experiment and to be included in the question."'(S1)

"The manipulative helps us to determine the kind of variables involved in the experiment. It helps us to determine whether the questions we ask are operational or action questions."(S30)

"More ideas come out about the variables which can be investigated while manipulating the circuits."(S23)

"The manipulative - electrical circuit help us to test whether the question that we generated can be answered or did the question is logic to be answered. Besides that, the manipulative also helps us to construct questions by observing and manipulating the variables in the circuit."'(S28)

"The manipulative helps us to think of different variables which can be investigated in the experiment."(S21)

"We are more confident in generating questions. More ideas come out about the variables which can be investigated while manipulating the circuits."(S18)

It appeared that the manipulative had encouraged profound thinking about variables in the experiment. It had prompted students to think more deeply about the kind of variables that are feasible for investigations.

\section{The manipulative: Experiencing what students will inquire during an experiment}

Student teachers generally felt that the manipulative made them to notice what students would inquire during the experiment. Explanations for this were:

"The manipulative electrical circuit did help us to figure out the questions that we need to generate. We can experience the real situation of what students will inquire while conducting experiment."(S32) 
"I notice the feasibility of inquiry learning in this activity. I could construct suitable questions that encourage students to explore the electrical circuit and to experience inquiry approach in their learning, and make them to find answers by themselves."(S19)

Obviously these students had given some deep thought on what they learnt. The ability to relate the manipulative with inquiry learning showed that much can be learnt when student teachers were engaged in the community of inquiry.

In sum, almost all student teachers expressed that the EAM learning experience enabled them to generate productive questions at higher categories and cognitive levels. They also indicated the value of question stems and manipulative in prompting them to think of possible responses to a question and the kind of variables that are feasible for investigations. On the whole, the findings in the written reflections aligned with those generated questions upon subsequent intervention.

\section{Discussion}

The findings of this study show that physics student teachers who typically did not generate productive questions spontaneously were capable of generating such questions when prompted to do so. This is evident at later stages of the activities when the students were able to pose productive questions of higher thinking level and categories upon further scaffolding using Elstgeest (1985)'s and Alfke's (1974) question stems and manipulative. This suggests that the acquisition of the productive question-asking skill is gradual: student teachers will not spontaneously pose productive questions unless they are stimulated to think about such questions. In order to do so, they need to engage in the community of inquiry, a manipulative to stimulate their thoughts, and scaffolding from the question stems. The EMA strategy can be one way to stimulate productive question-asking at high thinking levels. This is indicated by the finding that student teachers started asking higher level thinking questions, which dealt with causal relationships between variables after the specific intervention.

The reason for these phenomena is the nature of the EAM strategy in which the student teachers were exposed to the whole procedure of scientific inquiry. Student teachers who were exposed to experimental setting started to initiate a process of hypothesizing, predicting, thought-experimenting, and recognizing cause and effect relationship. The rich experience with the electrical circuit and its electrical components would have given them plenty to think about and to question. Symington (1980)'s finding share the same view that letting students enjoy a period of unstructured observation with materials increased the number of questions they were able to ask. The format of the question stems controlled the quality of the specific questions student teachers asked, and that those questions, in turn, influenced the level of student teachers thinking during discussion. This is also supported by King (1994)'s finding who found that giving students thought-provoking question stems helped them to generate higher cognitive questions. The combination of manipulative (procedural knowledge) and Elstgeest (1985)'s and Alfke's (1974) questioning model (declarative knowledge) allowed a variety of possibilities and combinations in formulating productive questions and, therefore, resulted in a substantial increase in student teachers' question-posing capabilities.

\section{Conclusions}

In sum, the use of the EAM strategy in this study has increased the physics student teachers' ability to generate productive questions at higher categories and level of thinking. The use of question stems of Elstgeest (1985)'s and Alfke's (1974) questioning model with 
Nyet Moi SIEW, Sopiah ABDULLAH. The Impact of Elstgeest and Alfke's Questioning Model with Manipulatives on Physics Student Teachers' Ability to Generate Productive Questions

PROBLEMS

OF EDUCATION

IN THE $21^{\text {st }}$ CENTURY

Volume 54, 2013

110 manipulative that were provided to student teachers contributed to a substantial increase of their ability in generating causal relationship-type questions. The findings suggest that students can ask productive questions that stimulate inquiry before performing a laboratory activity. Students' questions play an important role in the nature of their inquiry and thus they need to be encouraged. Teachers cannot simply rely on students' spontaneous questioning and should explicitly orient their students toward asking questions, for example, by specifically involving them in the community of inquiry to generate productive questions using EAM strategy. This will help students to direct their own inquiry and use these questions as a springboard for their further investigation and discussion.

\section{References}

Agresti, A. (1990). Categorical Data Analysis. New York: Wiley.

Alfke, D. (1974). Asking operational questions: A basic skill for science inquiry. Science and Children, 11 (17), 18-19.

Bloom, B. S. (1956). Taxonomy of educational objectives: The classification of educational goals: Handbook I, cognitive domain. New York; Toronto: Longmans, Green.

Chin, C. (2002). Open Investigations in Science: Posing problems and asking investigative questions. Teaching and Learning, 23 (2), 155-166.

Dillon, J. T. (1984). The classification of research questions. Review of Educational Research, 54 (3), $327-361$.

Elstgeest, J. (1985). The right question at the right time. In W. Harlen (Eds.), Primary Science: Taking the plunge (pp. 36-46). Oxford, England: Heinemann.

Fisher, R. (1998). Teaching thinking: Philosophical inquiry in the classroom. London: Continuum.

Harlen, W. (1996). The teaching of science in primary schools. London: David Fulton Publishers, Ltd.

Jelly, S. (1985). Helping children raise questions and answering them. In W. Harlen (Eds.), Primary Science: Taking the Plunge (pp. 47-57). London: Heinemann.

King, A. (1994). Guiding knowledge construction in the classroom: Effects of teaching children how to question and how to explain. American Educational Research Journal, 31 (2), 338-368.

Ling, A. Y. (2000, September). Implementing an inquiry-based primary science curriculum in Malaysia. Paper presented at the Seminar Penyelidikan Pendidikan Zon Sabah, Kota Kinabalu, Malaysia.

Lipman, M. (1988). Critical thinking - what can it be? Journal of Educational leadership, 46 (1), 38-43.

Matthews, G. B. (1984). Dialogues with Children. Cambridge, Massachusetts: Harvard University Press.

Ministry of Education Malaysia (2006). The Form Five Physics Curriculum Specification: Integrated Curriculum for Secondary Schools. Kuala Lumpur: Curriculum Development Center.

Rescher, N. (1982). Empirical Inquiry. London: Athlone.

Subahan, M. M. T. (1999). Dampak Penyelidikan Pembelajaran Sains terhadap Perubahan Kurikulum. Universiti Kebangsaan Malaysia. Retrieved May 11, 2013, from http://www.penerbit.ukm.my/ dampak.pdf

Symington, D. J. (1980). Scientific problems seen by primary school pupils (Unpublished Doctoral dissertation). Monash University, Australia.

White, R. T. (1977). An overlooked objective. Australian Science Teachers'Journal, 23 (2), 124-125. 
Elstgeest (1985)'s and Alfke (1974)'s categories of questions and Question

PROBLEMS

OF EDUCATION

IN THE $21^{\text {st }}$ CENTURY

Volume 54, 2013

\begin{tabular}{|c|c|}
\hline Category of Question and Description & Question Stems \\
\hline $\begin{array}{l}\text { Attention Focusing Questions } \\
\text { These questions help learners take note of some significant } \\
\text { detail which might easily be overlooked during initial explora- } \\
\text { tion of new materials. }\end{array}$ & $\begin{array}{l}\text { - What do you notice about ......? } \\
\text { - What have you seen...? } \\
\text { - Do you notice...?" followed by "What is it?" "What } \\
\text { does it do?" } \\
\text { - How would you describe the feel of it? }\end{array}$ \\
\hline $\begin{array}{l}\text { Measuring and Counting Questions } \\
\text { These questions engage students to use new skills and learn } \\
\text { to use new instruments and to strive for greater accuracy and } \\
\text { precision in their observations. }\end{array}$ & $\begin{array}{l}\text { - How many...? } \\
\text { - How long...? } \\
\text { - How often...? }\end{array}$ \\
\hline $\begin{array}{l}\text { Comparison Questions } \\
\text { These questions direct students to observe differences in } \\
\text { shape, size, color, etc., and recognize these differences as } \\
\text { valuable information. }\end{array}$ & $\begin{array}{l}\text { - Is this bigger, heavier, stronger, more _then? } \\
\text { - How are they alike and how are they different? } \\
\text { - In how many ways are these objects alike and how } \\
\text { do they differ?" }\end{array}$ \\
\hline
\end{tabular}

\section{Action Questions}

This question category helps children discover relationships between what they do and the reaction of the materials they are handling. Probing lets students explore the properties of unfamiliar materials, forces at work and small events.

- What happens to .... if ...?

- What happens if you hold your magnet near a match?

- What happens if you throw a tiny piece of paper in a spider's web?

\section{Problem Posing Questions}

These questions build students' abilities to predict, problemsolve and form simple hypotheses that lead to verification. Questions must be preceded by a satisfactory exploration of the materials with which the learner works.

\section{Operational Questions \\ These questions help students manipulate variables in science} experiments through eliminating, substituting, and increasing or decreasing the presence of a variable.
- Can you find a way to...?

- How would you make an object .......?

- Can you find a way to make a sinking object float?

- How would you separate salt from water?

- How would ..... be if.......?

1) If we did not heat the pan of water, would the water rise as far in the strip of paper towelling? (Elimination of a variable).

2) Would the water rise higher in a strip of newspaper or in a paper towel? (Substitution of a variable) 3) Would the water rise higher on a piece of paper towelling or a narrow piece of towelling? (Increase of a variable)

Adapted from Elstgeest, J. (1985). The right question at the right time. In Harlen, W. (1985) (Ed.). Primary Science: Taking the plunge. Oxford: Heinemann.

\section{Advised by Renata Bilbokaite, University of Siauliai, Lithuania}

